\title{
THIRD WORLD COUNTRIES (TWC) RESEARCH PUBLICATIONS BY DISCIPLINES: A COUNTRY-BY-COUNTRY CITATION ANALYSIS
}

\author{
FARIDEH OSAREH,* CONCEPCIÓN S. WILSON** \\ School of Information, Library and Archive Studies, University of New South Wales, \\ Sydney, NSW 2052 (Australia)
}

(Received February 18, 1997)

\begin{abstract}
This paper discusses the publications of Third World Countries (TWC) in the Science Citation Index by disciplines. TWC documents which were nationally cross-linked at least 20 times were identified and their citing documents categorised into seven disciplines. The top 12 TWC are discussed vis-à-vis their population, Gross National Product, and the extent of participation using observed rates of contribution in each discipline and expected rates based on numbers of citations received. Brazil, Mexico, Argentina and Chile, appeared most frequently in the top five ranks in each of the seven disciplines; however, none of these countries had neither the largest population nor the highest GNP per capita. Overall observed rates exceeded expected rates in all but two disciplines: Biomedicine and Agriculture. Physics \& Engineering had the highest overall observed rate with the top five TWC exceeding the overall and their individual expected rates. Brazil and Venezuela led by exceeding their expected rates in four of the seven disciplines.
\end{abstract}

\section{Introduction}

One of the most striking features of recent scholarly activities is the accelerated globalisation of scientific research. ${ }^{1}$ The universal norm of science is international and independent of scientific findings. ${ }^{2}$ It seems, therefore, that the participation of Third World Countries (TWC) in the international enterprise of creating new knowledge in science is desirable; otherwise, many of the researchers in these countries may move away from mainstream science ${ }^{3-4}$ or move to non-TWC to conduct research. The TWC scientific research activities were investigated by Garfield in $1983 .{ }^{5}$ A more up-to-date

\footnotetext{
* Currently at: Department of Library Sciences, School of Education and Psychology, Shahid Chamran University, Ahwaz (Iran).

** To whom all correspondence should be directed.
} 
picture of TWC research publications over the last decade is needed. To this end, a paper on the productivity and impact of the TWC was presented in the Fifth International Conference of ISSI. ${ }^{6}$ Using the initial data gathered for the earlier paper, this study further examines the TWC research publications over major disciplinary fields, using country-by-country or citing-cited linkage analysis. The top Third World countries in each discipline were identified through a broad subject analysis of the journals in which the TWC citing-cited papers were published. The nationally crosslinked participation of the TWC in the various broad disciplines are compared according to their populations and GNP per capita. The extent of participation of each of the top 12 TWC in the major disciplines was determined by comparing each TWC observed rates in each discipline to their overall expected rates based on the number of citations received.

This paper raises the following questions:

- Which of the TWC were the most highly cross-linked countries?

- Did the most highly cross-linked documents share common topics or subject areas; if so, what are these subject areas?

- Were TWC the leaders of other TWC in one or more specific subject area?

- How do the top TWC in the various subject areas compare vis-à-vis population size and GNP per capita?

- To what extent did the top TWC equal or exceed their expected (citing) rates in each of the broad subject areas?

\section{Methodology}

Using the Science Citation Index (SCI) this study investigated citing-cited linkages by country; the citations received (citing documents) from 1985-1993 for ten percent of the source publications (cited documents) from 1985-1989 were identified for analysis. The citing documents were examined to develop disciplinary profiles through a broad subject classification of journals in which the citing documents were published. Citing-cited linkage is the relationship between a citing paper and a cited paper and this relationship is an important indicator of communication behaviour. ${ }^{7}$ Using citing-cited linkage analysis, a matrix was constructed for TWC documents cross-linked at least 20 times. $^{8}$

Before creating the final citing-cited linkage matrix, ten percent of the TWC source documents which were cited at least ten times were identified: 1038 source documents from 70 countries and over one-half of the total number of citations. These citing-cited, nationally cross-linked documents were analysed country-by-country, and cross- 
linkages of at least 20 times were selected. From an initial total of 37394 citing documents, 21555 were to TWC publications receiving at least 10 citations. From these 21555 citing documents only 15771 were nationally cross-linked at least 20 times. The final citing-cited matrix of both highly cited source documents and highly cross-linked by country included 42 Third World cited countries and 43 citing countries. The journals in which these 15771 citing documents were published were analysed according to their subject fields. The subject fields of citing journals were identified using the Institute for Scientific Information (ISI) subject categories. ${ }^{9}$ There were 128 scientific subfields ${ }^{10}$ and these subfields aggregated into seven major fields as follows: 11

1. Biomedicine and Biochemistry.

2. Agriculture, agronomy, botany, entomology, ecology, animal and food science.

3. Physics and material science and engineering.

4. Chemistry.

5. Social and behavioral sciences and psychiatry.

6. Mathematics and computer science.

7. Geosciences.

To determine the level of participation of each of the top 12 TWC over the seven major fields, the expected rate or level of participation was calculated as the percentage of the number of citations received by each of the 42 highly cross-linked cited TWC over the total number of citations received (15771). The national distribution effort for each of the 42 TWC over the seven broad subject areas (that is, the observed rate) was calculated as the percentage of the number of citations received in each of the seven broad subject areas for each of the top 12 TWC over the total number of citations ascribed to the particular subject area. ${ }^{12}$ For example, Brazil had an expected rate of 21.1 (that is, it received 3321 of the total 15771 citations) and an observed rate of 19.1 in the field of Biomedicine and Biochemistry (that is, it received 1733 of the total 9081 citations in this field). Thus it can be inferred that Brazil's observed rate or level of participation (19.1) in the field of Biomedicine and Biochemistry did not meet its expected rate (21.1).

\section{Results and discussion}

This section is based on the results obtained from the citing-cited matrix of 42 Third World cited countries which were cross-linked at least 20 times with 43 citing countries. Of the 43 citing countries, 21 were TWC and 22 were non-TWC. Of the 21 
citing TWC, only two (Taiwan and South Africa) were not amongst the 42 'highly' cross-linked Third World cited countries.

Figure 1 is based on the citing-cited matrix; it shows the cumulative distribution of the 15771 citing documents and identifies the eleven countries contributing nearly $80 \%$ of the citations, with the US contributing about $40 \%$ of all citing documents. All but one (Malawi) of the 'highly' cross-linked TWC received at least 20 citings from the US; however, citings to Brazil (1085) and Mexico (905) from the US accounted for nearly one-third. The third and fourth ranked citing countries, Brazil and Argentina, showed a reciprocal relationship in their citations: $96 \%$ of each country's citing documents were country-self-citings; and the remaining $4 \%$ were citings to each other. Mexico and Chile were also predominantly country-self-citers, $96 \%$ and $92 \%$ respectively; however both countries then distributed their remaining citations to Brazil. Sixteen of the 21 Third World citing countries were totally (100\%) country-self-citers, including South Korea which ranked tenth.

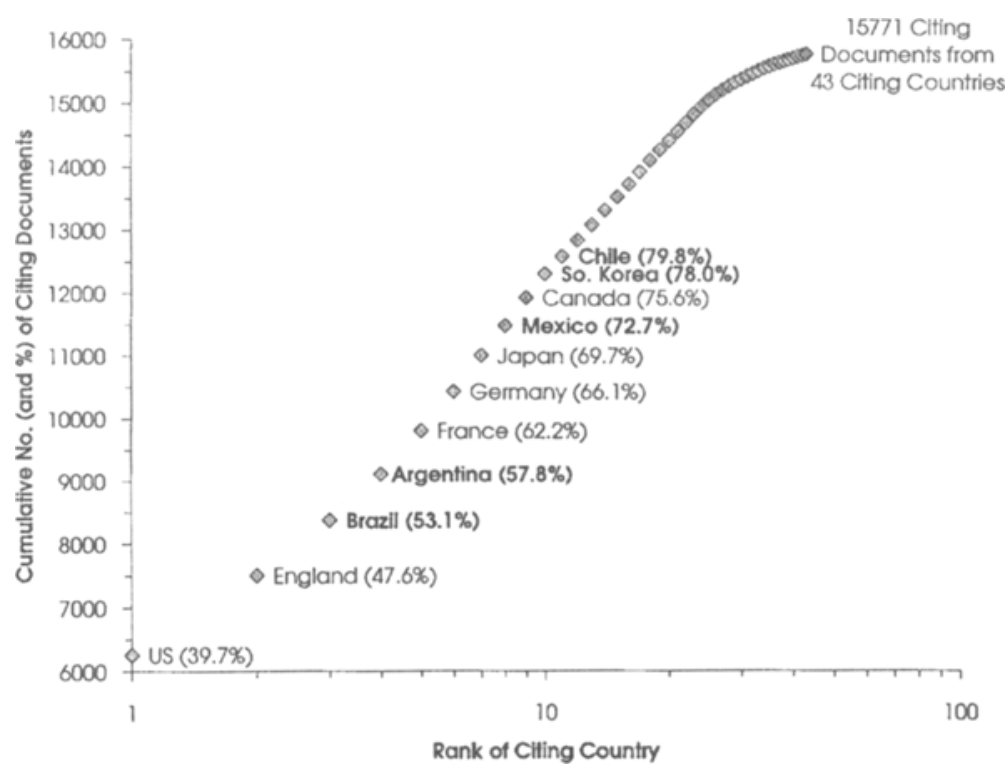

Fig. 1. Distribution of 15771 citing documents from 43 citing countries: the top eleven citing countries are identified, along with cumulative percentages. Five of the eleven countries (bolded) are TWC 
Table 1 (column 1) lists the 42 cited TWC in the citing-cited matrix and shows the distribution over the seven broad subject disciplines according to the journals which published the 15771 citing documents. As can be seen, over half $(57.6 \%)$ of the documents are in the Biomedicine and Biochemistry fields, $18.4 \%$ in Physics and Engineering, $11.4 \%$ in Chemistry, $6.6 \%$ in Agriculture and related subjects, $3.7 \%$ in Geosciences, $1.6 \%$ in Mathematics and Computer Sciences and $0.8 \%$ in the Social and Behavioral Sciences. It is not surprising that over 9000 citing documents were published in journals classified broadly in Biomedicine and Biochemistry; of the 1849 journals citing. TWC source publications, the top three, Lancet, Transactions of the Royal Society of Tropical Medicine and Hygiene and the Journal of Infectious Diseases, are biomedical journals. At the other end of the distribution, it is equally not surprising that there are only 127 citing documents published in the Social and Behavioral Sciences journals. This study only used the Science Citation Index (SCI); the Social Science Citation Index (SSC), in combination with the Science Citation Index (SCI), would be a better measure to determine the citedness of documents in this broad subject discipline.

Table 1

Numbers and percentages of citing documents $(\mathrm{n}-15771)$ by broad subject areas in Science of the 42 'highly' Third World cross-linked countries. The 12 bolded TWC in the first column appear as one of the top five TWC in at least one of the seven subject areas. The seven bolded percentages in the various \% cells represent the TWC with the highest citing-cited linkages in the seven subject areas. The last row of bolded percentages represents the distribution of citing documents through the seven subject areas in decreasing order

\begin{tabular}{|c|c|c|c|c|c|c|c|c|c|c|c|c|c|c|}
\hline & \multicolumn{2}{|c|}{$\begin{array}{c}\text { Biomedicine \& } \\
\text { Biochemistry }\end{array}$} & \multicolumn{2}{|c|}{$\begin{array}{l}\text { Physics \& } \\
\text { Engineering }\end{array}$} & \multicolumn{2}{|c|}{ Chemistry } & \multicolumn{2}{|c|}{$\begin{array}{l}\text { Agricultural } \\
\text { Scieṇces }\end{array}$} & \multicolumn{2}{|c|}{ Geosciences } & \multicolumn{2}{|c|}{$\begin{array}{l}\text { Mathematics \& } \\
\text { Computer Sci. }\end{array}$} & \multicolumn{2}{|c|}{$\begin{array}{c}\text { Social \& } \\
\text { Behav. Sci. }\end{array}$} \\
\hline & No. & $\%$ & No. & $\%$ & No. & $\%$ & No. & $\%$ & No. & $\%$ & No. & $\%$ & No. & $\%$ \\
\hline Algeria & 101 & 1.1 & 7 & 0.2 & 0 & 0.0 & 0 & 0.0 & 0 & 0.0 & 0 & 0.0 & 0 & 0.0 \\
\hline Argentina & 731 & 8.1 & 414 & 14.3 & 227 & 12.7 & 89 & 8.6 & 12 & 2.0 & 75 & 30.1 & 7 & 5.5 \\
\hline Bangladesh & 72 & 0.8 & 11 & 0.4 & 0 & 0.0 & 3 & 0.3 & 0 & 0.0 & 0 & 0.0 & 0 & 0.0 \\
\hline Brazil & 1733 & 19.1 & 961 & 33.1 & 225 & 12.5 & 113 & 10.9 & 162 & 28.0 & 82 & 32.9 & 45 & 35.4 \\
\hline Chile & 657 & 7.2 & 417 & 14.4 & 134 & 7.5 & 43 & 4.1 & 22 & 3.8 & 1 & 0.4 & 13 & 10.2 \\
\hline Colombia & 69 & 0.8 & 17 & 0.6 & 1 & 0.1 & 0 & 0.0 & 0 & 0.0 & 0 & 0.0 & 1 & 0.8 \\
\hline Costa Rica & 55 & 0.6 & 0 & 0.0 & 94 & 5.2 & 14 & 1.4 & 7 & 1.2 & 0 & 0.0 & 0 & 0.0 \\
\hline Egypt & 196 & 2.2 & 49 & 1.7 & 159 & 8.9 & 28 & 2.7 & 0 & 0.0 & 33 & 13.3 & 0 & 0.0 \\
\hline Ethiopia & 29 & 0.3 & 0 & 0.0 & 0 & 0.0 & 0 & 0.0 & 0 & 0.0 & 0 & 0.0 & 0 & 0.0 \\
\hline Guatemala & 41 & 0.5 & 0 & 0.0 & 0 & 0.0 & 0 & 0.0 & 0 & 0.0 & 0 & 0.0 & 0 & 0.0 \\
\hline Indonesia & 44 & 0.5 & 7 & 0.2 & 0 & 0.0 & 6 & 0.6 & 35 & 6.0 & 0 & 0.0 & 0 & 0.0 \\
\hline Iran & 22 & 0.2 & 3 & 0.1 & 0 & 0.0 & 0 & 0.0 & 0 & 0.0 & 0 & 0.0 & 0 & 0.0 \\
\hline Ivary Coast & 27 & 0.3 & 6 & 0.2 & 0 & 0.0 & 0 & 0.0 & 0 & 0.0 & 0 & 0.0 & 0 & 0.0 \\
\hline Jamaica & 135 & 1.5 & 0 & 0.0 & 0 & 0.0 & 1 & 0.1 & 0 & 0.0 & 0 & 0.0 & 0 & 0.0 \\
\hline
\end{tabular}


F. OSAREH, C. S. WILSON: TWC PUBLICATIONS BY DISCIPLINES

Table I. (Cont.)

\begin{tabular}{|c|c|c|c|c|c|c|c|c|c|c|c|c|c|c|}
\hline & \multicolumn{2}{|c|}{$\begin{array}{l}\text { Biomedicine \& } \\
\text { Biochemistry }\end{array}$} & \multicolumn{2}{|c|}{$\begin{array}{l}\text { Physics \& } \\
\text { Engineering }\end{array}$} & \multicolumn{2}{|c|}{ Chemistry } & \multicolumn{2}{|c|}{$\begin{array}{l}\text { Agricuitural } \\
\text { Sciences }\end{array}$} & \multicolumn{2}{|c|}{ Geosciences } & \multicolumn{2}{|c|}{$\begin{array}{l}\text { Mathematies \& } \\
\text { Computer Sci. }\end{array}$} & \multicolumn{2}{|c|}{$\begin{array}{l}\text { Social \& } \\
\text { Behav. Sci. }\end{array}$} \\
\hline & No. & $\%$ & No. & $\%$ & No. & $\%$ & No. & $\%$ & No. & $\%$ & No. & $\%$ & No. & $\%$ \\
\hline Kenya & 955 & 10.5 & 0 & 0.0 & 11 & 0.6 & 110 & 10.6 & 10 & 1.7 & 0 & 0.0 & 19 & 15.0 \\
\hline Kuwait & 155 & 1.7 & 0 & 0.0 & 5 & 0.3 & 5 & 0.5 & 0 & 0.0 & 1 & 0.4 & 0 & 0.0 \\
\hline Lebanon & 34 & 0.4 & 17 & 0.6 & 0 & 0.0 & 0 & 0.0 & 0 & 0.0 & 0 & 0.0 & 0 & 0.0 \\
\hline Malawi & 12 & 0.1 & 0 & 0.0 & 2 & 0.1 & 7 & 0.7 & 0 & 0.0 & 0 & 0.0 & 0 & 0.0 \\
\hline Malasia & 33 & 0.4 & 2 & 0.1 & 8 & 0.5 & 21 & 2.0 & 0 & 0.0 & 0 & 0.0 & 0 & 0.0 \\
\hline Mexico & 1537 & 16.9 & 491 & 16.9 & 105 & 5.9 & 157 & 15.1 & 108 & 18.0 & 27 & 10.8 & 16 & 12.6 \\
\hline Morrocco & 10 & 0.1 & 1 & 0.0 & 27 & 1.5 & 0 & 0.0 & 0 & 0.0 & 0 & 0.0 & 0 & 0.0 \\
\hline Nepal & 8 & 0.1 & 0 & 0.0 & 1 & 0.1 & 0 & 0.0 & 11 & 1.9 & 0 & 0.0 & 0 & 0.0 \\
\hline Nigeria & 49 & 0.5 & 4 & 0.1 & 22 & 1.2 & 46 & 4.4 & 1 & 0.2 & 0 & 0.0 & 0 & 0.0 \\
\hline Pakistan & 17 & 0.2 & 15 & 0.5 & 8 & 0.5 & 30 & 2.9 & 31 & 5.3 & 0 & 0.0 & 0 & 0.0 \\
\hline Panama & 80 & 0.9 & 3 & 0.1 & 0 & 0.0 & 13 & 1.3 & 0 & 0.0 & 0 & 0.0 & 5 & 3.9 \\
\hline Papua New Guine & eal 67 & 1.8 & 0 & 0.0 & 1 & 0.1 & 2 & 0.2 & 27 & 4.6 & 0 & 0.0 & 0 & 0.0 \\
\hline Peru & 108 & 1.2 & 2 & 0.1 & 0 & 0.0 & 11 & 1.1 & 18 & 3.1 & 0 & 0.0 & 0 & 0.0 \\
\hline Phillippines & 100 & 1.1 & 1 & 0.0 & 4 & 0.2 & 68 & 6.6 & 0 & 0.0 & 0 & 0.0 & 0 & 0.0 \\
\hline Rwanda & 22 & 0.2 & 0 & 0.0 & 0 & 0.0 & 0 & 0.0 & 0 & 0.0 & 0 & 0.0 & 0 & 0.0 \\
\hline Saudi Arabia & 404 & 4.4 & 49 & 1.7 & 36 & 2.0 & 11 & 1.1 & 70 & 12.0 & 2 & 0.8 & 2 & 1.6 \\
\hline Singapore & 153 & 1.7 & 22 & 0.8 . & 59 & 3.3 & 32 & 3.1 & 17 & 2.9 & 0 & 0.0 & 0 & 0.0 \\
\hline So. Korea & 404 & 4.4 & 286 & 9.9 & 503 & 28.1 & 62 & 6.0 & 0 & 0.0 & 14 & 5.6 & 0 & 0.0 \\
\hline Sri Lanka & 42 & 0.5 & 0 & 0.0 & 1 & 0.1 & 21 & 2.0 & 0 & 0.0 & 0 & 0.0 & 0 & 0.0 \\
\hline Tanzania & 49 & 0.5 & 0 & 0.0 & 3 & 0.2 & 1 & 0.1 & 0 & 0.0 & 0 & 0.0 & 1 & 0.8 \\
\hline Thailand & 256 & 2.8 & 3 & 0.1 & 4 & 0.2 & 17 & 1.6 & 0 & 0.0 & 0 & 0.0 & 0 & 0.0 \\
\hline Trinidad \& Tobag & go 22 & 0.2 & 0 & 0.0 & 0 & 0.0 & 1 & 0.1 & 0 & 0.0 & 0 & 0.0 & 0 & 0.0 \\
\hline Tunisia & 44 & 0.5 & 8 & 0.3 & 13 & 0.7 & 0 & 0.0 & 0 & 0.0 & 7 & 2.8 & 0 & 0.0 \\
\hline Turkey & 129 & 1.4 & 46 & 1.6 & 80 & 4.5 & 27 & 2.6 & 19 & 3.2 & 7 & 2.8 & 2 & 1.6 \\
\hline Venezuela & 144 & 1.6 & 56 & 1.9 & 53 & 3.0 & 64 & 6.2 & 28 & 4.8 & 0 & 0.0 & 15 & 11.8 \\
\hline Zaire & 187 & 2.1 & 0 & 0.0 & 0 & 0.0 & 1 & 0.1 & 0 & 0.0 & 0 & 0.0 & 1 & 0.8 \\
\hline Zambia & 30 & 0.3 & 1 & 0.0 & 0 & 0.0 & 0 & 0.0 & 7 & 1.2 & 0 & 0.0 & 0 & 0.0 \\
\hline Zimbabwe & 18 & 0.2 & 0 & 0.0 & 7 & 0.4 & 33 & 3.2 & 0 & 0.0 & 0 & 0.0 & 0 & 0.0 \\
\hline $\begin{array}{l}\text { Total no. citing } \\
\text { docs. }\end{array}$ & 9081 & & 99 & & 793 & & 37 & & 35 & & 249 & & 127 & \\
\hline $\begin{array}{c}\% \text { of total citation } \\
(n=15771) \text { in broa } \\
\text { subject areas }\end{array}$ & & 57.6 & & 18.4 & & 11.4 & & 6.6 & & 3.7 & & 1.6 & & 0.8 \\
\hline
\end{tabular}

Table 1 also indicates the number and percentage of citing documents for each of the 42 'highly' cited TWC over each of the seven subject areas. In column 1 , the top 12 cited TWC are bolded and will be analysed more closely below. These 12 TWC appear as one of the top five TWC in at least one of the seven subject disciplines; additionally, 
five of these TWC appear among the top eleven citing countries (see also Fig. 1). For each broad discipline, the highest percentage of citing documents are highlighted.

Table 2 provides a closer examination of these top 12 cross-linked TWC. The crosslinked TWC are arranged in decreasing order of rank weighted totals. A simple weighting system was devised where rank one was assigned five points; rank two was assigned four points, etc. The highest rank weighted total that any one country can received would therefore be 35 if the country was ranked first in all of the seven scientific disciplines; alternately, the lowest rank weighted total would be one if a country was ranked fifth in only one of the seven scientific disciplines. Brazil clearly leads in overall rank weighted totals (32) as well as in the breadth of its citing documents over all of the seven scientific disciplines. No other TWC placed in one of the top five ranks over all seven subject disciplines. In general Latin American countries can be seen as leading countries in all of the seven disciplines; only in the areas of Chemistry and the Social Sciences are non-Latin American countries ranked first (South Korea in Chemistry) or second (Kenya in the Social Sciences). In all other areas, Latin American countries are ranked either first or second.

Table 2

Cross-linked TWC ranked in the top five of one or more of the seven broad disciplines. The numbers in each of the scientific discipline row cells show the top ranking TWC (from one to five). The italicised and bolded numbers in the last row are the rank weighted totals for each of the twelve TWC, where $\operatorname{rank} 1=5 ; \operatorname{rank} 2=4$; etc.

\begin{tabular}{|c|c|c|c|c|c|c|c|c|c|c|c|c|}
\hline & \multicolumn{12}{|c|}{ Cited Countries } \\
\hline & 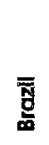 & $\frac{\mathbf{g}}{\underset{\mathbf{S}}{\mathbf{S}}}$ & 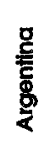 & 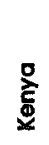 & $\begin{array}{l}\mathbf{o} \\
\mathbf{8} \\
\mathbf{0} \\
\dot{8}\end{array}$ & $\frac{\Phi}{\frac{1}{\delta}}$ & 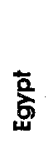 & 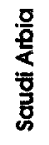 & 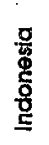 & 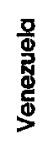 & 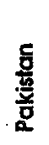 & 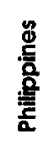 \\
\hline \multicolumn{13}{|l|}{ Sclentific Disciplines } \\
\hline Biomedicine \& Biochemistry & 1 & 2 & 4 & 3 & & 5 & & & & & & \\
\hline Physics \& Engineering & 1 & 2 & 4 & & 5 & 3 & & & & & & \\
\hline Chemistry & 3 & & 2 & & 1 & 5 & 4 & & & & & \\
\hline Agriculture \& Related subjects & 2 & 1 & 4 & 3 & & & & & & & & 5 \\
\hline Geosciences & 1 & 2 & & & & & & 3 & 4 & & 5 & \\
\hline Mathematics \& Compter Sclence & 1 & 4 & 2 & & 5 & & 3 & & & & & \\
\hline Social \& Behavioural Sciences \& Psychiatry & 1 & 3 & & 2 & & 5 & & & & 4 & & \\
\hline Rank weighteo totals & 32 & 22 & 14 & 10 & 7 & 6 & 5 & 3 & 2 & 2 & 1 & $I$ \\
\hline
\end{tabular}


A comparison of these 12 TWC over the seven scientific disciplines with respect to their populations and Gross National Product (GNP) per capita ${ }^{13}$ reveals some interesting observations. Figure 2 shows the 1990 population and the 1989 GNP for the $12 \mathrm{TWC}$, as well as the number of scientific disciplines in which each of the 12 TWC ranked in the top five. For example, Brazil had a population of c. 152.5 Million, GNP per capita of c. US\$ 2550 and ranked as one of the top five TWC over all seven (7) disciplines.

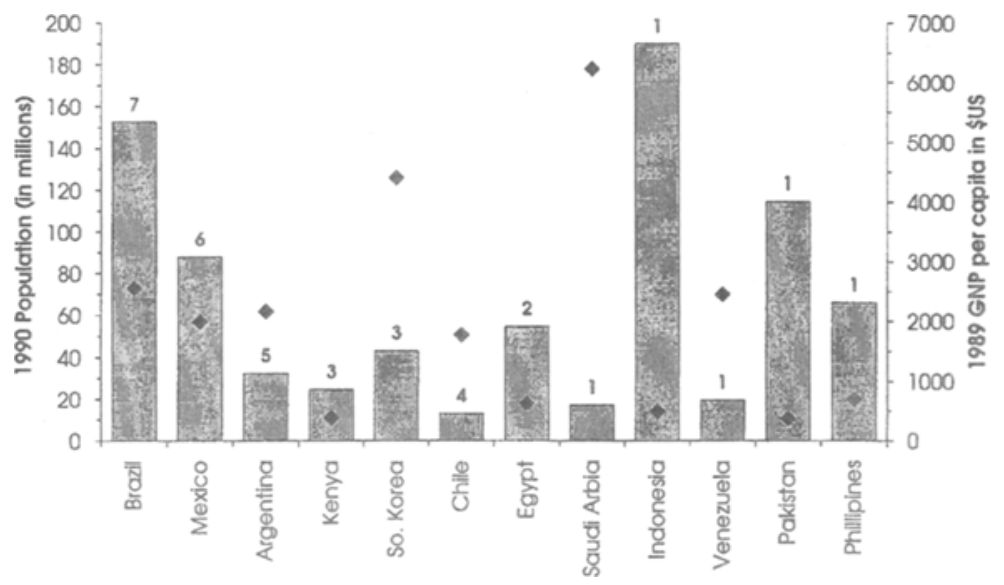

Fig. 2. The top 12 cross-linked TWC arranged in relative ranking order according to their weighted totals versus population (bars) and GNP per capita (diamonds). The bolded numbers ( 1 to 7 ) above each TWC's population bar shows the number of scientific disciplines in which each of the 12 TWC ranked in the top five

Indonesia with the largest population appears in the top ranks in only one subject field (Geosciences), while Brazil with a lower population ranked in all seven subject fields; however, Brazil's GNP is about five times higher. Chile appears as one of the leading countries, because with the lowest population and only c. US\$1770 GNP per capita, it is represented as one of the top five countries in four (4) fields (see also Table 2). According to population, Pakistan and the Philippines were not as effective compared to Egypt which has a smaller population than either of the two TWC but has been more cross-linked in two (2) scientific fields (Chemistry and Mathematics and Computer Sciences). In considering GNP per capita, Saudi Arabia and South Korea ranked first (US\$ 6230) and second (US\$ 4400), respectively; however, neither country 
is particularly broadly represented in the citing documents over the seven subject areas. However, as noted above, South Korea did rank first in Chemistry and fifth in Physics and Engineering as well as Mathematics and Computer Science. On the other hand, Saudi Arabia featured in only one (1) discipline; it ranked third in Geosciences - a not unexpected outcome considering the country's interest in geological activities. In contrast to South Korea's relatively high GNP, Kenya with nearly the lowest GNP (US\$ 380) and population size (24.6 Million) is one of the top five TWC in three (3) subject areas: Biomedicine and Biochemistry, Agriculture and related subjects, and the Social and Behavioural Sciences.

Again the Latin American countries (especially Brazil, Mexico, Argentina and Chile) appear to be 'leaders' in most of the subject areas: their GNPs are only about one-third to one-half that of Saudi Arabia and South Korea. Additionally, none of the Latin American countries have the highest population. The following questions therefore can be asked. What element(s) affected these four Latin American countries to perform comparatively better than the other top TWC? Could the cooperation of these countries with the European Community International Scientific Cooperation (ISC) program be regarded as a reason for their success? ${ }^{14}$ Lewison and his colleagues $^{15}$ indicate the increase of co-authorship between several European Community member states, notably France and Spain, with Latin American countries; this has resulted in a number of joint scientific publications. Are there other reasons? Finding explanations for the relatively high achievement levels of the Latin American countries may be instructive to the rest of the TWC.

To address the last question dealing with the participation of the top 12 TWC in each of the broad subject areas, the expected rate or level of participation for each TWC was calculated based on the proportion of citations each TWC received vis-à-vis the overall total number of citations received (15771) by the 42 'highly' cross-linked TWC. Table 3 gives the number of citations received (row one) and the expected rates in percentages (row two) for each of the top $12 \mathrm{TWC}$ in decreasing order. In the following rows, each of the seven broad disciplines show each TWC's number of citations received and their observed rates in percentages. The last column gives the total overall number of citations received (12743) and the overall expected rate of 80.8 for these top 12 TWC. The remaining numbers and percentages break down the numbers of citations received in each of the seven broad disciplines from the top 12 TWC and their corresponding observed rates in percentages. From the last column one can see that in all but two disciplines, Biomedicine \& Biochemistry and the Agricultural Sciences, these 12 TWC exceeded the overall expected rate. This finding is somewhat surprising as one would expect that these two broad applied subject areas would be of major 
concern to most TWC. Physics \& Engineering had the highest overall observed rate and the top five TWC all exceeded their individual expected rates. This finding is also unexpected unless the citing documents in the broad field of Physics \& Engineering are mostly concerned with the more applied area of Engineering. Brazil and Venezuela each exceeded the expected rates in four of the seven broad disciplines; the remaining TWC exceeded or equalled their expected rates in from one to three broad disciplines.

Rank order by number of citations received and expected rates (\%) of the top twelve cross-linked TWCs. Across seven broad disciplinary fields, observed rates (\%) which equal or exceed expected rates (\%) for each TWC and for the overall total of the 12 TWCs are bolded

\begin{tabular}{|c|c|c|c|c|c|c|c|c|c|c|c|c|c|}
\hline $\begin{array}{l}\text { Number of Citations } \\
\text { Received and } \% \\
\text { Expected Rates overall; } \\
\text { Observed Rates over } 7 \\
\text { dlsciplines for top } 12 \\
\text { WCs }\end{array}$ & 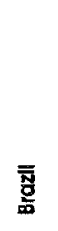 & $\begin{array}{l}\frac{8}{x} \\
\frac{\mathbf{0}}{\mathbf{2}}\end{array}$ & 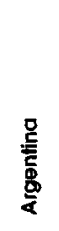 & $\stackrel{D}{\vec{E}}$ & $\begin{array}{l}\text { g } \\
\frac{0}{0} \\
\stackrel{8}{8}\end{array}$ & 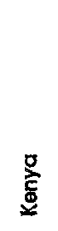 & 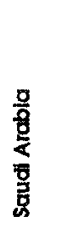 & 点 & 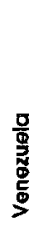 & 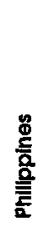 & $\frac{\text { c }}{\frac{5}{5}}$ & 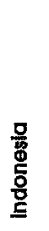 & $\begin{array}{c}\text { Total No. } \\
\text { Cltations } \\
\text { Recelved; } \\
\text { Total } \% \\
\text { Exp. and } \\
\text { Obs. Rotes } \\
\text { for top } 12 \\
\text { MC5 }\end{array}$ \\
\hline No. Citations Racelved & 3321 & 2441 & 1555 & 1287 & 1269 & 1105 & 574 & 465 & 360 & 173 & 101 & 92 & 12743 \\
\hline \% Expected Rate & 21.7 & 15.5 & 9.9 & 8.2 & 8.0 & 7.0 & 3.6 & 2.9 & 2.3 & 3.1 & 0.6 & 0.6 & 80.8 \\
\hline Blomed. \& Blochem. & 1733 & 1537 & 731 & 657 & 404 & 955 & 404 & 190 & 144 & 100 & 17 & 44 & 6922 \\
\hline \% Observed Rate & 19.1 & 18.9 & 8.0 & 7.2 & 4.4 & 10.5 & 4.4 & 2.2 & 1.6 & 1.1 & 0.2 & 0.5 & 76.2 \\
\hline Physics \& Engineesing & 961 & 491 & 414 & 417 & 286 & 0 & 49 & 49 & 56 & 1 & 15 & 7 & 2746 \\
\hline * Observed Rate & 33.1 & 16.9 & 14.3 & 144 & 9.9 & 0.0 & 1.7 & 1.7 & 1.9 & 0.0 & 0.5 & 0.2 & 94.7 \\
\hline Chemistry & 225 & 105 & 227 & 134 & 503 & 11 & 36 & 159 & 53 & 4 & 8 & 0 & 1465 \\
\hline \% Observed Rate & 12.5 & 5.9 & 12.7 & 7.5 & 28.1 & 0.6 & 2.0 & 6.9 & 3.0 & 0.2 & 0.4 & 0.0 & 81.7 \\
\hline Agricultural Scl. & 113 & 157 & 89 & 43 & 62 & 110 & 11 & 28 & 64 & 68 & 30 & 6 & 781 \\
\hline \% Observed Rate & 10.9 & 15.1 & 8.6 & 4.1 & 6.0 & 10.6 & 1.1 & 2.7 & 6.2 & 6.6 & 2.9 & 0.6 & 75.3 \\
\hline Geosciences & 162 & 108 & 12 & 22 & 0 & 10 & 70 & D & 28 & 0 & 31 & 35 & 478 \\
\hline \% Observed Rote & 27.7 & 18.5 & 2.1 & 3.8 & 0.0 & 1.7 & 12.0 & $0 . D$ & 9.8 & 0.0 & 5.3 & 6.0 & 81.7 \\
\hline Maths. \& Comp. Scl. & 82 & 27 & 75 & I & 14 & 0 & 2 & 33 & 0 & 0 & D & 0 & 234 \\
\hline \% Observed Rate & 32.9 & 10.8 & 30.1 & 0.4 & 5.6 & 0.0 & 0.8 & 13.3 & 0,0 & 0.0 & 0.0 & 0.0 & 94,0 \\
\hline Soc. \& Beh. Scl. & 45 & 16 & 7 & 13 & 0 & 19 & 2 & 0 & 15 & 0 & 0 & 0 & 117 \\
\hline \% Observed Rate & 35.4 & 12.6 & 5.5 & 10.2 & 0.0 & 15.0 & 1.6 & 0.0 & 11.8 & 0.0 & 0.0 & 0.0 & 92.1 \\
\hline
\end{tabular}

From Table 1 which shows all of the 42 TWC's participation in each of the seven broad disciplines, one can see that six of these countries participated throughout all the 
seven subject areas: Argentina, Brazil, Chile, Mexico, Saudi Arabia and Turkey. Of these countries, only Turkey does not appear in the top 12 TWC ranked in the top five of one or more of the seven broad disciplines (see Table 2); however, like Brazil and Venezuela, Turkey exceeded its expected rate of about 2.0 in four of the seven broad disciplines. Three countries, Ethiopia, Guatemala and Rwanda, are only represented in one discipline - Biomedicine \& Biochemistry. A quick scan of the columns in Table 1 representing the numbers and percentages of citations in each of the seven fields shows that there are a number of non-participation (that is, zeroes) even in these 42 'highly' cross-linked TWC. If all the expected and observed rates for these 42 TWC were calculated, there would be a significant number of TWC where the observed rates are far below their expected rates. None of the TWC equalled or exceeded their expected rates in all of the seven broad disciplines.

\section{Conclusions and implications}

This study found that of 126 TWC, 42 countries (excluding India ${ }^{16}$ ) were crosslinked at least 20 times with 43 citing countries: 21 TWC and 22 non-TWC. There were 15771 citing documents in the country citing-cited matrix. The journals (1849) which published the citing documents were categorised into seven broad scientific disciplines. The subject analysis of citing documents (through the journals) showed that only 12 TWC ranked in the top five in at least one of the seven scientific disciplines. Of these 12 TWC, four Latin American countries, Brazil, Mexico, Argentina and Chile, ranked in the top five in four or more of the seven subject disciplines. None of the Latin American countries had either the largest population or the highest GNP per capita. For these 12 TWC the level of participation showed that the overall observed rate exceeded the overall expected rate in all but two of the seven disciplines: Biomedicine \& Biochemistry and the Agricultural Sciences. The two Latin American countries, Brazil and Venezuela led by exceeding their expected rates in four of the seven broad disciplines. In summary, of this study it is apparent that during the study period TWC (excluding India) did not make a significant contribution to science as evidenced by the Science Citation Index. Some explanations and reasons for this conclusion are given below.

In the section Trends in Scientific Communication, of Scientific American, Gibbs reported on the findings revealed from interviews with over 100 scientists and journal editors throughout the developing world. ${ }^{17}$ One of the objectives of the report is to uncover the obstacles which appear to be preventing some TWC researchers from sharing their discoveries with the industrial world and with one another. One major problem identified is the quality of the journals published in TWC. Gibbs reports, for 
example, that according to K.C. Garg of the National Institute of Science, Technology and Development Studies in New Delhi, only about 20\% of some 1500 journals published in India are refereed and appeared regularly. Meneghini from Brazil reports that almost all of the c. 400 Brazilian scientific journals have either a 'very lenient editorial policy or none at all'. The shortage of qualified TWC referees and the limited access to foreign (non-TWC) experts as referees lead to infrequent checking of either the accuracy of the methods or the author's knowledge of the scientific literature. One interviewee from the Philippines went on to say that some local journals may even be harmful by perpetuating the wrong research practices. One conclusion which can be made is that much of the (modest) TWC research funds are wasted. The deficiencies in research publications are also related to the cost of publication of research journals. With the rise of electronic journals, one could conclude that the problems associated with printed journals (including cost) will be alleviated. However, this is not so since a number of TWC do not have the necessary infrastructure to sustain the activities of electronic publishing.

Another problem associated with research activities is the publication exchange patterns of Third World scientists: they tend not to cite each other ${ }^{18}$ and publish important findings in overseas journals. The later means that domestic journals can not gain prestige and/or have international circulation. There is also the problem of the variety of languages of the TWC. Although most TWC scientist try to publish important findings in the international, English language journals, generally these scientists do not speak English as their first language. Consequently, the obstacle of writing in English is still a major problem for most scientists in the TWC.

Although this study has shown that certain TWC (especially Latin American countries) are indeed 'leaders' (among TWC) in various subject disciplines as shown by the citing-cited linkages, this perception is only relative. If the global research activities as reported through the publications indexed by the $S C I$ and other major A\&I Services, e.g. MEDLINE, INSPEC, etc. are considered, then the TWC participation would be about two percent, even though nearly one-quarter of the world's scientists are from the TWC.

There are a number of incentive programs to help overcome the imbalance. The United Nations has sponsored three commercial indexes of Third World journals. Several TWC institutions have incentive programs that reward their scientists for publishing in peer-reviewed journals; some even require publication in journals indexed in SCI for promotion! Alternately, a number of TWC have reward systems to encourage their scientists to publish in local journals and to maintain the standards of these journals. Perhaps the most promising development is the movement of mainstream 
scientific publishing onto the Internet. If international organisations such as UNESCO can ensure that scientists from TWC can have full Internet access at the lowest possible rate, then a number of the problems mentioned above can be resolved and scientific communication can be truly global. However, as mentioned earlier, a shift to electronic journals and electronic publishing can only happen if (and when) an adequate telecommunication infrastructure is in place in all the TWC.

\section{References and notes}

1. P. BOURKE, L. Butler, B. BIGLIA, Monitoring Research in the Periphery: Australia and the ISI Indices, Research evaluation and policy project monograph series No. 3. Canberra, Research School of Social Sciences, The Australian National University, 1996, p. 1.

2. B. CRONIN, The Citation Process: The Role and Significance of Citations in Scientific Communication, Oxford: Taylor Graham, 1984, p. 17.

3. S. ARUNACHALAM, K. MANORAMA, Are citation-based quantitative techniques adequate for measuring science on the periphery? Scientometrics, 15 (1989) 393-408.

4. S. ARUNACHALAM, K. MANORAMA, How do journals on the periphery compare with mainstream scientific journals? Scientometrics, 14 (1988) 83-95.

5. E. GARFIELD, Mapping science in the Third World, Science and Public Policy, 10 (1983) No. 3 , $112-127$.

6. F. OSAREH, C. S. WILSON, Scientific productivity and impact of the Third World Countries (TWC): A citation study. In: Proceedings of the Fifth International Conference of the International Society for Scientometrics and Informetrics. Rosary College. June 7-10, 1995. Medford, N.I., Learned Information, 1995, pp. 403-412.

7. B. REEVES, C. BORGMAN, A bibliometric evaluation of core journals in communication research, Human Communication Research, 10 (1983) No. 1, 119-136.

8. A detailed explanation of the data collection procedures and methodology can be obtained from the following PhD dissertation: F. OSAREH, Evaluation and Measurement of Third World Countries' Research Publications: A Citation and Country-by-Country Citation Study. PhD Dissertation. Sydney, NSW, Australia, University of New South Wales, School of Information, Library and Archive Studies, 1996.

9. Science Citation Index 1985-1989: Five Year Cumulation: an International Interdisciplinary Index to the Literature of Science, Medicine, Agriculture, Technology, and the Behavioral Sciences, Guide and lists of source publications, Philadelphia, ISI Press, 1991, pp. 113-131.

10. H. SMALL, E. GARFIELD, The geography of science: disciplinary and national mapping, Journal of Information Science, 11 (1985) No. 4, 147-159.

11. For aggregating the 128 subfields to seven major fields, the Library of Congress Subject Heading (LCSH) 15th ed. 1992 was used as a guide to find out which subfield belonged to which ISI scientific field. The subject fields of the documents which were published in a multidisciplinary journal were inspected and added to the appropriate field in each file for each country.

12 Calculations for observed and expected rates are based on Small \& Garfield, 1985, p. 151. See reference in footnote [10] above.

13 G. T. KURIAN (Ed.) Encyclopedia of the Third World, 4th ed. New York, Facts on File, 3 vols, 1992. 
14. This program was started in the mid-1980s; it was intended to form links between scientists in the European Community (EC) and their colleagues in the Asian, Latin American and Mediterranean (ALAMed) countries. The program provides one-year post-doctoral fellowships to ALAMed scientists to visit an EC laboratory for planning joint research projects; holds workshops to focus and stimulate research; and helps in the submission of fellowships and research project proposals. See Ref. 13 below.

15. G. LEWISON, A. FAWCETT-JONES, C. KESSLER, Latin American scientific output 1986-91 and international co-authorship patterns, Scientometrics, 27 (1993) 317-336.

16. Reasons for exclusion of India were articulated in the paper by Osareh \& Wilson (1995). See Ref. 6 above.

17. W. W. GiBBS, Lost science in the Third World, Scientific American, 273 (1995) No. 2, 76-83.

18. In this study, the high country self-citing reported refers only to publications which are in internationally refereed journals and therefore are indexed by the Science Citation Index as source publications; these publications do not include 'domestic' journals. 